\title{
A INFLUÊNCIA DO SISTEMA DE AVALIAÇÃO DA AACSB NA GESTÃ̃ DOS PROGRAMAS DE PÓS-GRADUAÇÃO STRICTO SENSU EM ADMINISTRAÇÃo NOS ESTADOS UNIDOS
}

\author{
Emerson Antonio Maccari \\ emersonmaccari@gmail.com \\ Universidade Nove de Julho - São Paulo, SP / Brasil \\ Edson Luiz Riccio \\ elriccio@usp.br \\ Universidade de São Paulo - São Paulo, SP / Brasil \\ Cibele Barsalini Martins \\ cibelebm@uol.com \\ Universidade Nove de Julho - São Paulo, SP / Brasil
}

Recebido em 31/10/2012

Aprovado em 10/10/2013

Disponibilizado em 01/12/2013

Avaliado pelo sistema double blind review

Revista Eletrônica de Administração

Editor: Luís Felipe Nascimento

ISSN 1413-2311 (versão on-line)

Editada pela Escola de Administração da Universidade Federal do Rio Grande do Sul.

Periodicidade: Quadrimestral

Sistema requerido: Adobe Acrobat Reader.

\section{RESUMO}

Nos últimos anos percebe-se a preocupação das Instituições de Ensino Superior - IES no aprimoramento e monitoramento do desempenho dos seus cursos de pós-graduação, por meio de sistemas de avaliação. Para aprimorar o entendimento do sistema de avaliação da pósgraduação no Brasil, é importante estudar os sistemas de avaliação de países que possuem experiência em avaliação ao longo dos anos. O artigo tem como objetivo identificar a influência do sistema de avaliação da Association to Advance Collegiate School of Business (AACSB) na gestão dos programas de pós-graduação em administração dos Estados Unidos. $\mathrm{O}$ método de pesquisa foi o estudo de casos múltiplos, em quatro programas de PósGraduação credenciados pela AACSB. Os principais resultados indicam que os programas utilizam o sistema da AACSB para assegurar o cumprimento de sua missão no contexto de cada programa atua. Os programas precisam atender a um padrão mínimo de qualidade, nos moldes do sistema ISO. Existe pouca exigência para produção científica por parte dos professores que podem ser credenciados com o perfil acadêmico ou profissional, respeitando os limites impostos pelo sistema. Existe uma grande exigência do sistema para que os programas atendam as necessidades dos stakeholders. Nesse sentido, a formação adequada do aluno e seu desenvolvimento profissional são tratados com profissionalismo pelos programas, pois parte importante de sua reputação é advinda da atuação do egresso do programa na sociedade.

Palavras-chave: Sistema de Avaliação; AACSB; Pós-Graduação; Credenciamento. REAd | Porto Alegre - Edição 76 - N 3 - setembro/dezembro 2013 - p. 738-766 


\title{
THE INFLUENCE OF THE AACSB EVALUATION SYSTEM ON THE MANAGEMENT OF GRADUATE PROGRAMS IN THE AMERICAN BUSINESS FIELD
}

\begin{abstract}
In the last few years concern of Higher Education Institutions regarding the improvement and the monitoring of the performance of its graduate courses through evaluations systems has been noticeable. In order to improve the understanding of graduate program evaluation systems in Brazil, it is important to study the evaluation systems of countries which have more experience in evaluation techniques throughout the years. The goal of this paper is to identify the Influence of the Association to Advance Collegiate School of Business (AACSB) evaluation system on the management of graduate programs in the American business field. The method of research was a study of multiple cases, in four Graduate programs accredited by the AACSB. The main results indicate that the programs use the system of AACSB to ensure the fulfillment of its mission in the context of each program operates. The programs must meet a minimum standard of quality, similar to the ISO system. There is little demand for scientific production by teachers that can be accredited with academic or professional profile, within the limits imposed by the system. There is a great system requirement for programs to meet stakeholder needs. In this sense, the proper training of the student and their professional development are handled with professionalism by the programs, because an important part of his reputation is arising from the performance of former students in the society.
\end{abstract}

Keywords: Evaluation Systems; AACSB; Graduate; Qualification.

\section{INTRODUÇÃO}

A preocupação com a qualidade dos cursos ofertados pelas Instituições de Ensino Superior - IES tem origem no desajuste estrutural entre Estado, IES e Sociedade, pois as frequentes transformações sociais demandam novas ações por parte das IES em períodos de tempo cada vez menores, (RODRIGUES, 2003). Para o autor, as IES não conseguem responder adequadamente a tais demandas, ou modificar suas tradicionais estruturas e modos de funcionamento, sem um prévio processo de avaliação. Nesse sentido, para tomar decisões e direcionar esforços para a mudança, é preciso conhecer a situação corrente, as capacidades existentes e as que se devem construir. Assim, fica evidente que a avaliação é um mecanismo essencial para o desenvolvimento de sistemas, organizações e países (SCHWARTZMAN, 1990; DURHAM 1992, 2006; RODRIGUES, 2003).

As questões envolvendo o sistema de avaliação do ensino no Brasil, em especial os estudos sobre o sistema de avaliação da CAPES e a avaliação realizada nos programas de pós-

REAd | Porto Alegre - Edição 76 - N 3 - setembro/dezembro 2013 - p. 738-766 
A influência do sistema de avaliação da AACSB na gestão dos programas de Pós-Graduação

Stricto Sensu em Administração nos Estados Unidos

graduação brasileiro, vêm sendo discutidos e acompanhados com interesse por toda a comunidade acadêmica envolvida nesse processo, com destaque para os trabalhos de: Soares (2003); Spagnolo; Souza (2004); Davok (2006); Guimarães (2002); Maccari (2008), Maccari, et al., (2008), Maccari et al. (2009a), (2009b); Oliveira et al., (2008); Negret (2008); Sousa (2008); Canhada (2009); Mello, Crubellate e Rossoni (2010); Nascimento (2010), Martins et al., (2012), (2013).

Partindo-se do pressuposto de que a educação é um elemento essencial para o desenvolvimento de um país, considera-se oportuno estudar as experiências de gestão dos programas de pós-graduação americanos e, em particular, a influência que o sistema de avaliação da AACSB exerce na gestão dos programas na área de administração, em quatro programas credenciados pela AACSB e que se encontram em diferentes estágios de desenvolvimento e avaliação. A partir disso, nesta pesquisa busca-se responder à pergunta:

Como o sistema de avaliação da AACSB influencia a gestão dos Programas de PósGraduação Stricto Sensu em Administração nos Estados Unidos?

Para responder a essa questão de pesquisa, o trabalho apresenta o seguinte objetivo: Identificar a influência do sistema de avaliação da AACSB na gestão dos programas de pósgraduação em administração dos Estados Unidos.

A opção por estudar o sistema de avaliação da AACSB se deu por três motivos: (1) os Estados Unidos são reconhecidos pela qualidade do ensino superior, pois dentre as 15 melhores universidades do mundo, 11 são norte-americanas (TOPUNIVERSITIES, 2012); (2) a AACSB conta com um consolidado processo de avaliação na área de administração que vem sendo realizado desde 1919; e (3) o sistema de avaliação da AACSB está presente em mais de 50 países, sendo utilizado por mais de 680 instituições de ensino superior o que demonstra sua abrangência e aceitação, (AACSB, 2013a). Destaca-se que no Brasil a AACSB está presente em duas Instituições de Ensino Superior - IES, a Fundação Getúlio Vargas FGV e o Insper Instituto de Ensino e Pesquisa.

O estudo se justifica pela contribuição no aprofundamento das discussões sobre a influência dos sistemas de avaliação na gestão dos programas de pós-graduação e suas consequências no desenvolvimento desses programas. Outro aspecto positivo diz respeito à possibilidade dos programas brasileiros aprenderem com as práticas de gestão adotadas pelos programas nos EUA, o que possibilita, em última análise, um aprimoramento na gestão dos programas no Brasil. Por fim, entende-se que o verdadeiro papel da avaliação, não pode ser o de vigiar e punir (FOUCAULT, 1983), mas sim, o de promover os parâmetros e as indicações

REAd | Porto Alegre - Edição 76 - N 3 - setembro/dezembro 2013 - p. 738-766 
Emerson Antonio Maccari, Edson Luiz Riccio \& Cibele Barsalini Martins

para o acompanhamento, desenvolvimento e aprimoramento dos programas que ele se presta a avaliar.

\section{AVALIAÇÃO DO SISTEMA EDUCACIONAL}

No início dos anos de 1990, as funções mais importantes da avaliação do sistema educacional estavam relacionadas à "gestão produtivista" do sistema educativo (AFONSO, 2000). Nos países anglo-saxônicos, as pessoas utilizam a avaliação como um instrumento auxiliar, mas fundamental, para escolher os cursos ou universidades que desejam estudar, contribuindo para estabelecer uma relação entre o processo avaliativo e a definição das políticas educacionais dos países (WILLIS, 1992).

Inicialmente, o objetivo da avaliação do sistema educacional foi documentar a necessidade de mudanças ou de demonstrar deficiências. Com o passar do tempo, percebeu-se que interesses e forças políticas afetavam este processo em vários países (HOUSE, 1992; ALLEN, 1995 e DURHAN, 1992, 2006). No entanto, nas duas últimas décadas a avaliação vem sendo utilizada como um meio de promover a reforma educacional (LINN, 1995, apud ALLEN, 1995).

Para Afonso (2000) e Durhan (1992), por meio de um sistema de avaliação que atenda as demandas da sociedade, o Estado reforça a credibilidade de suas ações. E, ainda, segundo os autores, a necessidade da avaliação ser realizada pelo Estado é mais visível em momentos em que há dúvidas ou incertezas sobre a recepção ou a consecução de determinadas políticas públicas.

Maccari (2008) adaptou o modelo explicativo sugerido por Contera (2002), que foi criado com base na proposta de Castrejón Diez (1991), sobre a relação entre a avaliação e a qualidade, conforme Figura 1.

REAd | Porto Alegre - Edição 76 - N 3 - setembro/dezembro 2013 - p. 738-766 
A influência do sistema de avaliação da AACSB na gestão dos programas de Pós-Graduação Stricto Sensu em Administração nos Estados Unidos

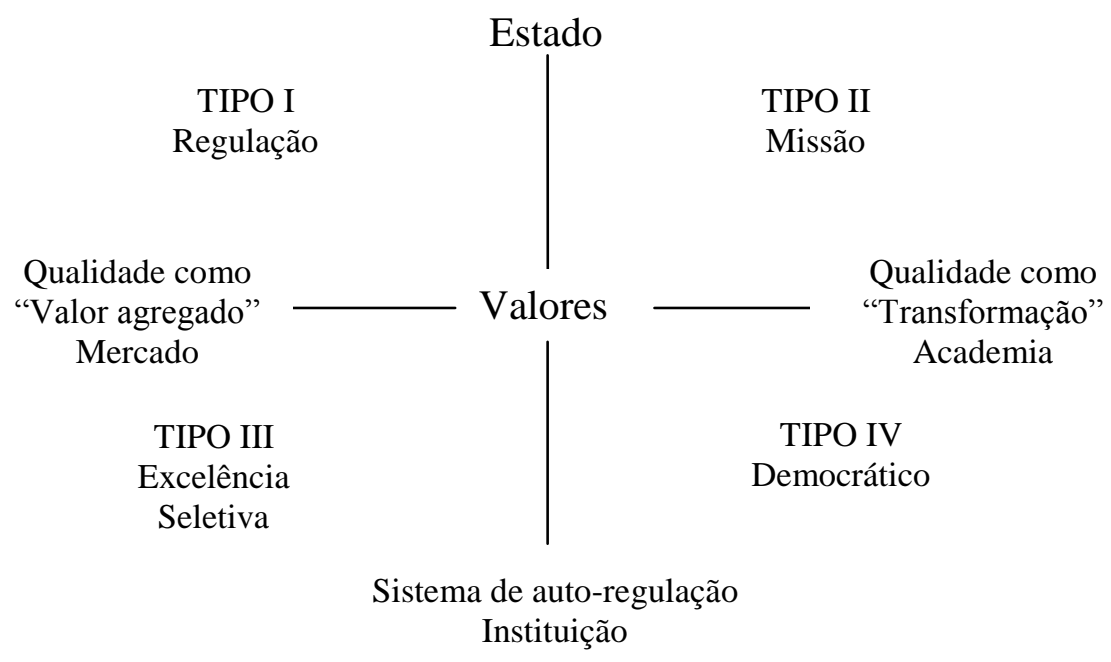

Figura 1 - Modelo de avaliação da qualidade da educação superior.

Fonte: Maccari, 2008.

Na Figura 1, o quadrante do Tipo I representa um sistema em que o Estado detém o controle do processo de avaliação e/ou credenciamento que se guia pela lógica do mercado. Conforme Roggero (2002), este sistema ocorre no Reino Unido, sem a Escócia, ao verificar que o sistema adotado tem como base de medição a concepção econômica da regulação pelo mercado. Para tanto, o Ministério da Educação e do Emprego criou dois organismos encarregados pelas avaliações das escolas inglesas no qual a concorrência entre as instituições de ensino era encorajada pela livre escolha dos pais.

O Tipo II se assemelha ao primeiro, mas a diferença é que neste caso o Estado recebe a contribuição de acadêmicos na definição dos quesitos de qualidade. Como exemplo, Oliveira (2009), Almeida Júnior e Catani (2009), Maccari (2008) citam o Sistema Nacional de Credenciamento da Argentina, do Brasil, da Colômbia e do Uruguai, em que a coordenação dos processos de reconhecimento da qualidade da educação superior é de responsabilidade do Estado.

Nesse modelo, o Estado vale-se da participação de professores designados por órgãos governamentais, colocando assim, a comunidade acadêmica como referência e valida a avaliação das instituições e programas. O foco neste modelo está justamente na auto-avaliação institucional e a avaliação de pares, o que legitima este processo.

No quadrante com o Tipo III são representados os processos de avaliações de instituições estatais ou não, que têm como objetivo principal a aproximação de padrões de qualidade definidos por agências internacionais com critério produtivista, (Afonso, 2000).

REAd | Porto Alegre - Edição 76 - N 3 - setembro/dezembro 2013 - p. 738-766 
Emerson Antonio Maccari, Edson Luiz Riccio \& Cibele Barsalini Martins

Neste sistema, a avaliação e o planejamento são utilizados para reestruturação e a realocação de recursos. Segundo Barrow (1996), neste modelo, por meio de contatos internacionais e do desenvolvimento de relações com indústrias e universidades de outros países, a pesquisa amplia e cresce, possibilitando aos acadêmicos a utilização do espaço institucional para realização de consultorias. Como exemplo, Wolff (1998) cita o sistema da avaliação dos Estados Unidos, que conforme a autora coloca este país na dianteira no desenvolvimento de uma ampla variedade de avaliações educacionais, para estabelecer níveis mínimos de competência para conclusão escolar, aferir no desempenho institucional, e para estabelecer padrões para medir o desempenho educacional em comparação com padrões internacionais.

O modelo de Tipo IV tem caráter emancipatório e proativo. Nele supõe-se a utilização de critérios éticos e requer um contexto que defenda a veracidade, a negociação e a vontade de aprofundar-se nas implicações da avaliação. Neste modelo, o clima institucional é importante, juntamente com a existência de culturas acadêmicas colaborativas e dispostas ao debate e à confrontação de ideias, assim como matrizes institucionais democráticas e uma percepção forte da necessidade de mudar.

\section{ENSINO SUPERIOR NOS ESTADOS UNIDOS}

De acordo com Durham (2006), o sistema educacional norte americano tem características bastante próprias, sendo um dos mais autônomos do mundo. Estudos recentes, principalmente pelos institutos que ranqueiam as melhores universidades, apontam para a excelência do modelo educacional do ensino superior dos Estados Unidos. É com base nesta informação que Hotson (2011) coloca em discussão os países que desejam melhorar suas universidades deveriam observar o modelo dos EUA, já que é no modelo deles que estão as melhores universidades.

A origem desse modelo de universidade decorre da instituição dos colleges, que eram escolas superiores voltadas à formação humanista geral e não ao credenciamento profissional (DURHAM, 2006). Os colleges forneciam títulos de bacharel em Artes (liberal Artes), os quais englobavam estudos nas áreas de História, Línguas, Ciências Políticas, Economia, Matemática Básica, Ciências, entre outras. A natureza dessas instituições não era pública nem estritamente confessional, eram escolas comunitárias semelhantes às fundações privadas. Sua criação envolvia a constituição de um fundo, levantado pela comunidade, com o qual se construíam os prédios e se provia um rendimento para manutenção do estabelecimento. Este

REAd | Porto Alegre - Edição 76 - N 3 - setembro/dezembro 2013 - p. 738-766 
A influência do sistema de avaliação da AACSB na gestão dos programas de Pós-Graduação Stricto Sensu em Administração nos Estados Unidos

rendimento era complementado pela cobrança de matrículas. Os colleges sobreviviam, principalmente, de doações feitas por pessoas físicas. Às vezes, também recebiam contribuições municipais. Este fundo público era administrado por um conselho curador constituído por indivíduos de fora da comunidade acadêmica, que podiam ser considerados como representantes da sociedade. Este modelo - que Durham (2006) denomina instituições públicas e não estatais - foi mantido quando o sistema evoluiu para incluir Universidades. No século XIX, os colleges serviram de base para a criação das Universidades estaduais públicas americanas, que também eram dirigidas por um conselho curador, de natureza não acadêmica.

Dentro desse sistema, as universidades estaduais contam com recursos provenientes de um fundo formado pelo governo estadual, complementado, conforme o caso, por doações municipais ou federais. Tais instituições são mantidas por repasses regulares dos respectivos governos estaduais; por doações privadas e por rendimentos provenientes de taxas de matrículas, pois não há ensino superior gratuito nos Estados Unidos. Todo o sistema é altamente descentralizado e possui quase total autonomia financeira e administrativa.

Nessa linha, Douglass (2010) contribuiu ao afirmar que na busca de atender a diferentes necessidades do país, os EUA constituíram um sistema educacional com uma abrangência que não se encontra em outra parte do mundo, e que a variedade e o número de colleges e universidades é um dos principais pontos fortes do sistema educacional do país. Segundo o autor, em 2010 havia 4350 instituições que concediam diplomas e certificados a aproximadamente 18 milhões de alunos. $\mathrm{O}$ autor ainda afirmou que os EUA foi o pioneiro na ideia de educação em massa.

Essa educação em massa aliada a fatores culturias explica em parte o bom desempenho do sistema universitário dos Estados Unidos, sendo um dos fatores mais importante à intensa competição por prestígio, por alunos promissores, por professores de renome internacional e por sucesso em competições esportivas (DURHAM, 2006). Este espírito competitivo envolve uma constante renovação de docentes e um empenho permanente para atrair graduados promissores para a formação profissional e pós-graduada. Esse processo generalizado de "caça-talentos" se deve ao fato de que o renome e a produção científica dos docentes são essenciais para o prestígio da instituição. Afinal é este prestígio que atrai doações de órgãos públicos e privados, alunos pagantes e financiamento para pesquisas, laboratórios e bibliotecas.

REAd | Porto Alegre - Edição 76 - N 3 - setembro/dezembro 2013 - p. 738-766 
Emerson Antonio Maccari, Edson Luiz Riccio \& Cibele Barsalini Martins

\subsection{Sistema de avaliação nos Estados Uunidos}

Nos Estados Unidos o processo de avaliação de escolas e programas de pósgraduação é realizado por organizações não-governamentais, (LARRY, 2002). Segundo o autor, existem dois tipos de avaliação educacional que são: (a) o institucional, avalia a qualidade institucional como um todo; e (b) o especializado, que examina os programas de pós-graduação em áreas específicas, com o intuito de verificar como esses programas preparam os estudantes para atuarem no mercado de trabalho, ou seja, o foco está na atuação e na contribuição do egresso para a sociedade. Um caso de sucesso em avaliação na área de administração é o da The Association to Advance Collegiate Schools of Business - AACSB, entidade que avalia e credencia as escolas, cursos e programas. Seu sistema de avaliação está consolidado e é amplamente utilizado mundo a fora.

\subsection{Sistema de avaliação da AACSB}

A AACSB é uma entidade sem fins lucrativos, que congrega instituições educacionais e outras organizações dedicadas à promoção e ao desenvolvimento da educação superior na área de Administração e Negócios, (AACSB, 2012a). Fundada em 1916, com o objetivo de assegurar o padrão de qualidade para as escolas de negócios dos Estados Unidos, sendo que, deu início ao processo de avaliação e credenciamento em 1919, com a adoção dos primeiros padrões de qualidade. Em 1980 foram adicionados ao sistema de avaliação da AACSB critérios de qualidade para a área de contabilidade. Em 1991 os membros da AACSB Internacional aprovaram os padrões de avaliação por pares (peer review). Essa ação trouxe mais credibilidade ao processo de avaliação e consequentemente, mais universidades começaram a utilizá-lo. No ano de 2003, seus membros aprovaram a revisão dos padrões considerados relevantes para todos os programas de Administração em nível global, apoiados na excelência na administração educacional. A última revisão nos critérios de avaliação ocorreu em 2013 após mais de dois anos de estudos em colaboração da comunidade internacional de gestão da educação.

Com essa filosofia, a AACSB busca cumprir sua missão que é "advances quality management education worlwide through accreditation, thought leadership, and value-added services." (AACSB, 2013b).

REAd | Porto Alegre - Edição 76 - N 3 - setembro/dezembro 2013 - p. 738-766 
A influência do sistema de avaliação da AACSB na gestão dos programas de Pós-Graduação Stricto Sensu em Administração nos Estados Unidos

Segundo Miles, Hazeldine e Munilla (2004), a AACSB mudou seu sistema de avaliação em decorrência, principalmente, da entrada de novos competidores no segmento de credenciamento. Um exemplo disso foi o início do credenciamento pela European Foundation for Management Development (EQUIS), que forçou a AACSB a reavaliar seu processo de avaliação e credenciamento. Com as mudanças, o processo de avaliação passou a ser baseado na missão e no contínuo desenvolvimento do programa. Destaca-se que os novos critérios levam em consideração que cada programa possui missões distintas e únicas e com diferentes expectativas de resultados. Assim, o novo processo possui três principais objetivos: a) uma abordagem sistemática de controle da qualidade total; b) esforços para um contínuo processo de desenvolvimento e avaliação de resultados; c) sistemas e processo para melhor gerenciar o relacionamento com os stakeholders.

Esses autores afirmam que o processo de avaliação e credenciamento da AACSB, assim como outros serviços prestados por estes credenciadores são similares ao propósito dos sistemas ISO 9000 e ISO 14000 das indústrias (que são associações de credenciamento voluntárias em nível global). Dessa forma, o credenciamento da AACSB está muito voltado ao processo, sendo o resultado, uma consequência desse processo e não o foco da avaliação propriamente dito.

Um aspecto importante do processo de avaliação e credenciamento das instituições educacionais e seus programas de pós-graduação na área de Administração e Contabilidade nos Estados Unidos é o fato dele ser voluntário e não governamental. No Brasil, por sua vez, o processo de avaliação da pós-graduação stricto sensu é diferente, sendo conduzido pela Coordenação de Aperfeiçoamento de Pessoal de Nível Superior - CAPES, que é ligada ao Ministério da Educação - MEC. Este processo, é obrigatório, sendo que a CAPES tem o poder de credenciar programas, autorizando-os para iniciarem seu funcionamento e reconhecendo os diplomas por eles expedidos.

De volta aos Estados Unidos, as instituições que são avaliadas e recebem o credenciamento da AACSB, necessitam comprovar seu comprometimento com a qualidade e o desenvolvimento contínuo dos seus programas. As exigências do sistema da AACSB são as seguintes: atender as necessidades dos stakeholders; administrar bem os recursos para atingir a missão; desenvolver o corpo docente; prover o mais alto padrão de ensino e da qualidade da matriz curricular; cultivar uma rica interação entre estudantes e professores; e formar alunos com alto padrão de qualidade conforme o especificado nos objetivos do curso (AACSB, 2012a).

REAd | Porto Alegre - Edição 76 - N 3 - setembro/dezembro 2013 - p. 738-766 
Emerson Antonio Maccari, Edson Luiz Riccio \& Cibele Barsalini Martins

Porém, para uma IES possuir o credenciamento da AACSB, ela deve cumprir uma série de requisitos e exigências formais do sistema de avaliação, além de efetuar as taxas e pagamentos anuais à AACSB para obter o credenciamento e, depois de credenciada, manterse no sistema.

\subsubsection{Valores Pagos para o Credenciamento da AACSB}

De acordo com AACSB (2012c), as IES que oferecem formação em Administração ou Contabilidade (graduação, mestrado ou doutorado) podem solicitar o credenciamento voluntariamente, mediante o pagamento das taxas. O processo inicial de credenciamento inclui uma avaliação própria por parte da instituição interessada e também uma avaliação por pares (peer review). Alcançando os critérios de credenciamento estabelecidos pela AACSB, a instituição passa a fazer parte do processo periódico de avaliação. Este processo tem por objetivo promover a evolução contínua do programa com vistas à manutenção do credenciamento. A tabela 1 ilustra os valores em dólares a serem pagos pelas instituições e programas.

Tabela 1 - Taxas para o credenciamento inicial e contínuo da AACSB

\begin{tabular}{l|r}
\multicolumn{1}{c|}{ DESCRIÇÃO DOS TIPOS DE TAXAS } & $\begin{array}{c}\text { VALOR } \\
\text { EM (U\$) }\end{array}$ \\
\hline Solicitação para preencher os formulários para credenciamento & 1.000 \\
\hline Pedido de pré-credenciamento para a área de Administração ou Contabilidade $^{(1)}$ & 4.500 \\
\hline Pedido pré-credenciamento para as áreas de Administração e Contabilidade ${ }^{(1)}$ & 7.300 \\
\hline Taxa anual para pré-credenciamento para a área de Administração ou Contabilidade ${ }^{(2)}$ & 4.500 \\
\hline Taxa anual para pré-credenciamento para as áreas de Administração e Contabilidade & 7.300 \\
\hline Início do processo para a área de Administração ou Contabilidade ${ }^{(3)}$ & 12.000 \\
\hline Início do processo para as áreas de Administração e Contabilidade & 18.500 \\
\hline Taxa anual Instituições credenciadas na área de Administração & 4.500 \\
\hline Taxa anual Instituições credenciadas nas áreas de Administração e Contabilidade & 7.300 \\
\hline
\end{tabular}

Legenda: (1) Inclui o ano fiscal corrente do pré-credenciamento; (2) Também aplicado a escolas em processo de credenciamento; (3) Valor a ser pago em seguida à submissão do processo inicial de credenciamento.

Fonte: AACSB. Accreditation Fees. Disponível http://www.aacsb.edu/accreditation/fees.asp. Acessado em 09 de fev de $2013 c$.

Observa-se na tabela acima que os valores para solicitar o credenciamento, manter-se credenciado e participar das avaliações são elevados. Porém, o processo de acompanhamento e de avaliação da AACSB é bastante completo e detalhado, o que auxilia de forma decisiva os programas, cursos e escolas de negócio no seu desenvolvimento e aprimoramento. 
A influência do sistema de avaliação da AACSB na gestão dos programas de Pós-Graduação Stricto Sensu em Administração nos Estados Unidos

\subsubsection{Processo de Avaliação e Credenciamento}

De acordo com AACSB (2013a) o credenciamento foca na qualidade da educação e os critérios indicam, de forma realista, as novas demandas na área de Administração, o que auxilia as escolas e programas de pós-graduação no seu contínuo desenvolvimento. A AACSB salienta que a avaliação e o credenciamento não criam automaticamente qualidade no processo de aprendizagem e na interação entre professores e alunos. Segundo ela, a qualidade advém de um contínuo e sistemático processo de desenvolvimento, sustentado pela instituição. Assim, o credenciamento observa, reconhece e, às vezes, motiva a criação da qualidade educacional dentro da instituição, (AACSB, 2013a).

De acordo com Maccari (2008) a AACSB implementa o processo inicial de credenciamento por meio da revisão do relatório da avaliação interna da IES e do relatório de visita do time de pareceristas ad hoc (peer review team). Por causa do vínculo entre missão do programa e o processo de credenciamento, é primordial para a decisão de credenciamento que os pareceristas levem em consideração os desvios entre a missão, os critérios da avaliação e as razões que provocaram isso. Alguns desvios observados no cumprimento de um determinado critério podem representar inovação ou diferenças culturais que ainda os critérios não levam em consideração. A avaliação precisa ser baseada na qualidade da experiência de aprendizagem e não em uma rígida interpretação dos critérios. Em outras palavras, a avaliação qualitativa e subjetiva tem um grande peso no processo de avaliação.

Dessa forma, o processo de avaliação e credenciamento leva em consideração: a) consistência/atualidade da matriz curricular; b) desenvolvimento do corpo docente; c) atividades de ensino; e d) atividade intelectual. Esses atributos determinam e direcionam os investimentos e o desenvolvimento do programa.

Os programas que alcançam o credenciamento passam por um processo contínuo de desenvolvimento, e objetivam a manutenção deste credenciamento, o qual é medido e acompanhado pelos seguintes instrumentos: a) relatório anual de atividades; b) sumário anual do plano estratégico; c) avaliação a cada cinco anos, sobre o progresso do programa. Esses relatórios são enviados pelos diretores ou coordenadores de programas com o intuito de assegurar a veracidade das informações e prover um processo de avaliação idônea.

Alguns requisitos são necessários para que as instituições possam pleitear o credenciamento. Elas necessitam oferecer cursos na área de Administração, baseados na qualidade e no valor real de formação de seus estudantes. Ademais, elas precisam demonstrar

REAd | Porto Alegre - Edição 76 - N 3 - setembro/dezembro 2013 - p. 738-766 
Emerson Antonio Maccari, Edson Luiz Riccio \& Cibele Barsalini Martins

e manter algumas características, tais como: a) comprovar suporte de recursos necessários para o bom andamento desses cursos; b) submeter todos os cursos ao processo de avaliação simultaneamente; c) demonstrar que a missão é consistente com o contexto cultural (diversidade de pessoas e ideias); d) estabelecer padrões éticos de conduta para seus administradores, professores e estudantes; e e) possuir cursos formando alunos há pelo menos dois anos ininterruptos.

A rigor, o credenciamento pode ser solicitado pela instituição (escola de negócio) quando pelo menos $25 \%$ das disciplinas lecionadas na graduação ou $50 \%$ das lecionadas nos cursos de pós-graduação estejam inseridas na temática da área de Administração. O credenciamento vale para toda a faculdade de administração, o que presume a inclusão de todos os graus de cursos e programas oferecidos por ela.

O sistema de credenciamento e avaliação da AACSB é composto por três critérios: 1) gestão estratégica; 2) participantes do processo de avaliação e 3) qualidade da aprendizagem. Esses critérios estão subdivididos e detalhados em itens, na sua grande maioria, de caráter qualitativo, que indicam os esforços do programa para o atendimento da missão. O quadro 1 ilustra os quesitos e itens desse sistema.

Quadro 1 - Quesitos de avaliação da AACSB

\begin{tabular}{|c|c|c|}
\hline QUESITO & DESDOBRAMENTO DE CADA QUESITO & AVALIAÇÃO \\
\hline 1 Gestão Estratégica & $\begin{array}{ll}1 \text { - } & \text { Definição da missão } \\
2 \text { - } & \text { Missão apropriada } \\
3 \text { - } & \text { Missão e os estudantes } \\
4 \text { - } & \text { Contínuo aprimoramento dos objetivos } \\
5 \text { - } & \text { Estratégia de financiamento }\end{array}$ & $\begin{array}{l}\text { Qualitativa } \\
\text { Qualitativa } \\
\text { Qualitativa } \\
\text { Qualitativa } \\
\text { Qualitativa }\end{array}$ \\
\hline $\begin{array}{l}2 \text { Participantes do } \\
\text { Processo de } \\
\text { Avaliação }\end{array}$ & $\begin{array}{ll}6 \text { - } & \text { Seleção de alunos } \\
7 \text { - } & \text { Formação dos alunos } \\
8 \text { - } & \text { Suporte aos alunos } \\
9- & \text { Número suficiente de professores } \\
10 \text { - } & \text { Qualificação dos professores } \\
11 \text { - } & \text { Administração e suporte aos professores } \\
12 \text { - } & \text { Professores, equipes de suporte e suas } \\
& \text { responsabilidades } \\
13 \text { - } & \text { Responsabilidades dos professores } \\
14- & \text { Responsabilidades dos alunos } \\
\end{array}$ & $\begin{array}{l}\text { Qualitativa } \\
\text { Qualitativa } \\
\text { Qualitativa } \\
\text { Qualitativa e Quantitativa } \\
\text { Qualitativa e Quantitativa } \\
\text { Qualitativa } \\
\text { Qualitativa } \\
\text { Qualitativa } \\
\text { Qualitativa }\end{array}$ \\
\hline $\begin{array}{l}3 \text { Garantia da } \\
\text { Qualidade da } \\
\text { Aprendizagem }\end{array}$ & $\begin{array}{l}15 \text { - Gestão da grade curricular } \\
16 \text { - Metas de aprendizagem para a graduação } \\
17 \text { - Nível de dedicação para o aluno de graduação } \\
18 \text { - Objetivos de aprendizagem para o Mestrado em } \\
\text { Administração Geral } \\
19 \text { - Objetivos de Aprendizagem para os Mestrados em } \\
\text { Administração de áreas específicas } \\
20 \text { - Exigências do Programa de Mestrado } \\
21 \text { - Objetivos do programa de doutorado }\end{array}$ & $\begin{array}{l}\text { Qualitativa } \\
\text { Não se aplica } \\
\text { Não se aplica } \\
\text { Qualitativa } \\
\text { Qualitativa } \\
\text { Qualitativa } \\
\text { Qualitativa }\end{array}$ \\
\hline
\end{tabular}

REAd | Porto Alegre - Edição 76 - № 3 - setembro/dezembro 2013 - p. 738-766 
A influência do sistema de avaliação da AACSB na gestão dos programas de Pós-Graduação Stricto Sensu em Administração nos Estados Unidos

Fonte: Maccari, 2008.

No quadro 1 acima, observa-se que o sistema de avaliação da AACSB leva em consideração a gestão da escola/programa, por meio do critério Gestão Estratégica. Esse critério é composto pelos itens relativos à missão, ao aprimoramento contínuo e às estratégias de financiamento. A definição da missão advém de um processo participativo que inclui o ponto de vista dos vários stakeholders; já o aprimoramento contínuo é avaliado por meio da especificação dos objetivos, metas e ações para sua execução; e possuir estratégias de financiamento e obtenção de recursos apropriados e suficientes para cumprir sua missão e ações especificadas no plano estratégico.

No sistema de avaliação da AACSB, percebe-se o enfoque dado aos processos, principalmente em relação aos critérios "participantes do processo de avaliação" e "garantia da qualidade". No primeiro, tem-se a preocupação com as políticas para a seleção de alunos nos cursos oferecidos, consistentes com a missão; no segundo, identifica-se o foco no processo sistemático de desenvolvimento, monitoramento, avaliação e revisão da grade curricular e seu impacto no processo de aprendizagem.

\section{MÉTODO DA PESQUISA}

Optou-se por utilizar a pesquisa qualitativa exploratória, que, de acordo com Eisenhardt (1989), viabiliza estudos com dados qualitativos, os quais são particularmente úteis quando se quer entender o porquê do relacionamento entre variáveis. A autora sugere que com a identificação desse relacionamento, os dados qualitativos geralmente proporcionam um bom entendimento das dinâmicas entre o porquê e o que está acontecendo. Além disso, o estudo apresenta ainda a característica de ser uma pesquisa realizada em um campo pouco explorado, pois há poucas pesquisas que tratam da influência dos sistemas de avaliação no desenvolvimento dos programas de pós-graduação stricto sensu em Administração, principalmente utilizando como base o sistema da AACSB.

Adicionalmente, utilizou-se o estudo de caso, com múltiplos casos, devido ao fato de esse tipo de análise tornar os resultados mais robustos (HERRIOTT; FIRESTONE, 1983). Destaca-se que a técnica de estudo de caso vem se desenvolvendo ao longo dos anos. Autores como Yin (1981, 1984, 1994, 2003), Eisenhardt (1989), Mintzberg e Waters (1982), entre outros, têm estudado e aperfeiçoado a técnica. Atualmente, este método tem sido utilizado nas mais diferentes situações, principalmente quando se deseja conhecer melhor um fenômeno e 
Emerson Antonio Maccari, Edson Luiz Riccio \& Cibele Barsalini Martins

suas inter-relações com o objeto em estudo. Para esta pesquisa, os casos foram selecionados com o intuito de prever uma replicação literal. Para isso, foram usados casos com características parecidas e um mesmo instrumento de coleta de dados.

A pesquisa teve dois componentes básicos estudados. O primeiro foi o documental, o qual foi realizado um estudo em profundidade do sistema de avaliação utilizado pela AACSB. O segundo elemento foi a pesquisa de campo, que buscou informações do uso do sistema de avaliação da AACSB, com o objetivo de descobrir como este sistema é usado pelos programas para o seu desenvolvimento.

Como instrumento de coleta de dados, utilizou-se a pesquisa semi-estruturada, pois, tem-se o conhecimento de que é mais provável que os pontos de vistas dos sujeitos entrevistados sejam expressos em uma situação de entrevista com planejamento relativamente aberto do que em uma entrevista padronizada ou por meio de um questionário (FLICK, 2004). Nessa direção, de acordo com Scheele e Groeben, apud Yin (2003) foram feitas perguntas controladas pela teoria, ou seja, questões voltadas para a literatura científica, correlatas com o tópico em questão.

Utilizou-se também uma mescla de métodos de coleta de dados, seguindo assim as recomendações de Eisenhardt (1989), que defende a utilização do método indutivo, mais flexível, que permite o ajuste ao longo do processo. Ademais, foram feitos algumas adequações ao instrumento de coleta de dados, na medida em que se foi estudando os casos. Isso foi importante, pois, de acordo com Harris e Sutton (1986), a flexibilidade permite ao pesquisador abordar temas emergentes observados na coleta e tire proveito desta oportunidade.

\subsection{Definição dos sujeitos sociais da pesquisa}

A escolha apropriada da população a ser pesquisada possibilita controlar as variações externas e definir os limites para generalização dos resultados. Nessa perspectiva, como este é um estudo multi-caso, os casos foram escolhidos intencionalmente, com base nas contribuições que eles poderiam fornecer ao estudo.

Posto isso, foram escolhidos quatro programas de pós-graduação stricto sensu em Administração dos Estados Unidos, sendo dois programas de universidades públicas com tradição em pesquisa, com cursos de mestrado e doutorado, que fazem parte do processo de credenciamento e avaliação da AACSB. Os outros dois programas são caracterizados como: um de uma instituição pública e um de uma instituição privada, sendo que ambos possuem

REAd | Porto Alegre - Edição 76 - N 3 - setembro/dezembro 2013 - p. 738-766 
A influência do sistema de avaliação da AACSB na gestão dos programas de Pós-Graduação

Stricto Sensu em Administração nos Estados Unidos

curso de mestrado em Administração e estão há menos tempo no processo de avaliação. Desta forma, pode-se observar a influência do sistema de avaliação da AACSB em cursos que estão em diferentes estágios de desenvolvimento. O quadro 2, a seguir, ilustra os programas de pósgraduação estudados nos Estados Unidos.

Quadro 2 - Programas de pós-graduação em Administração credenciados nos Estados Unidos pela AACSB

\begin{tabular}{|l|c|c|c|}
\hline \multicolumn{1}{|c|}{ Programa/universidade } & $\begin{array}{c}\text { Caracterís } \\
\text { tica }\end{array}$ & Cred. & Cursos \\
\hline Graduate Program of University of Massachusetts Amherst - UMASS & Pública & 1963 & $\mathrm{M} / \mathrm{D}$ \\
\hline Graduate Program of Cleveland State University - CSU & Pública & 1976 & $\mathrm{M} / \mathrm{D}$ \\
\hline Graduate Program of Central Connecticut State University - CCSU & Pública & 2001 & $\mathrm{M}$ \\
\hline Graduate Program of Quinnipiac University - QU & Privada & 2000 & $\mathrm{M}$ \\
\hline
\end{tabular}

Fonte: Os Autores

\subsection{Constructo da pesquisa}

Para a confecção do constructo da pesquisa, observou-se os preceitos de Eisenhardt (1989) e de Miles e Huberman (1994), visando constuir um instrumento de coleta de dados que levasse em consideração as características dos sistemas de avaliação dos Estados Unidos. Assim, o quadro a seguir descreve o constructo da pesquisa.

Quadro 3 - Constructo da pesquisa

\begin{tabular}{|c|c|c|c|}
\hline Objetivo da pesquisa & Cluster & Variáveis & Quest. \\
\hline \multirow{7}{*}{$\begin{array}{l}\text { Identificar a influência do sistema de } \\
\text { avaliação da AACSB na gestão dos } \\
\text { programas de pós-graduação em } \\
\text { administração dos Estados Unidos. }\end{array}$} & $\begin{array}{l}\text { Credenciamento } \\
\text { Recomendação }\end{array}$ & Necessidade e valor do credenciamento & 1 \\
\hline & \multirow{3}{*}{ Docentes } & Contratação de docentes & 3 \\
\hline & & Fluxo de docentes & 4 \\
\hline & & Equilíbrio das atividades & 5 \\
\hline & \multirow{2}{*}{$\begin{array}{l}\text { Discentes/ } \\
\text { Egresso }\end{array}$} & $\begin{array}{l}\text { Influência do sistema na formação, tempo } \\
\text { médio de titulação }\end{array}$ & 6 \\
\hline & & Acompanhamento do egresso & 7 \\
\hline & Inserção social & Ações para melhorar a inserção social & 8 \\
\hline
\end{tabular}

Fonte: Os Autores

\section{ANÁLISE E DISCUSSÃO DOS RESULTADOS}

Para responder a questão: Como o sistema de avaliação da AACSB influencia a gestão dos Programas de Pós-Graduação Stricto Sensu em Administração nos Estados Unidos, procedeu-se uma pesquisa com os diretores dos programas de pós-graduação em

REAd | Porto Alegre - Edição 76 - N 3 - setembro/dezembro 2013 - p. 738-766 
Emerson Antonio Maccari, Edson Luiz Riccio \& Cibele Barsalini Martins

Administração stricto sensu das universidades: University of Massachusetts Amherst (UMASS); Cleveland State University (CSU); Central Connecticut State University (CCSU)

e Quinnipiac University (QU). Na análise, foram utilizadas as siglas das instituições para representar os respondentes. Para facilitar o entendimento e a análise dos resultados, utilizouse a técnica de meta-matriz - sugerida por Miles e Huberman (1994) - para sintetizar e sumarizar, agrupando os resultados em clusters.

\subsection{Credenciamento - AACSB}

O processo de avaliação e credenciamento de escolas e programas de pós-graduação não é obrigatório nos Estados Unidos, sendo realizado por órgãos não-governamentais através de um processo de peer review (avaliação por pares). As IES e programas utilizam-se da avaliação para assegurarem o mínimo de qualidade em seu processo educacional. Nessa linha, os programas da área de Administração buscam credenciamento para assegurar a melhoria contínua da qualidade e a distinção em relação à concorrência. Esse processo de avaliação, no entanto, exige um grande esforço por parte da instituição para manutenção do credenciamento.

Já no Brasil, ter o credenciamento do curso perante a CAPES é um requisito legal, ou seja, a validade dos diplomas de mestrado e doutorado, em nível nacional, depende de o programa ter seus cursos reconhecidos e recomendados com nota igual ou superior a "3" na avaliação efetuada pela CAPES. Quando o curso obtém essa avaliação, isso indica que ele atende ao requisito mínimo de qualidade estabelecido pela legislação vigente, para que seja reconhecido pelo Ministério da Educação por meio do Conselho Nacional de Educação (CNE).

Quadro 4 - Necessidade de Credenciamento

\begin{tabular}{|l|l|}
\hline UMASS & $\begin{array}{l}\text { Estar credenciado traz muito trabalho, só é válido se houver distinção entre as escolas. Seria útil se } \\
\text { houvesse um ranking para distinguir mais os programas. }\end{array}$ \\
\hline CSU & $\begin{array}{l}\text { É importante para assegurar o processo de evolução continuada do programa e garantir o mínimo de } \\
\text { qualidade para atender aos anseios dos stakeholders. Há, também, a competição com outros } \\
\text { programas de escolas que estão credenciadas. }\end{array}$ \\
\hline CCSU & $\begin{array}{l}\text { Estar credenciado traz distinção para o programa, pois apenas 10\% das escolas de negócios estão } \\
\text { credenciadas e isso significa que você está entre os 10 mais. É também um fator de competição para } \\
\text { atrair alunos. }\end{array}$ \\
\hline QU & $\begin{array}{l}\text { Para um programa de uma escola particular é muito importante ter o credenciamento, pois nossa } \\
\text { mensalidade é mais cara que as públicas e estar credenciado indica um fator competitivo e que ajuda } \\
\text { na atração de alunos. }\end{array}$ \\
\hline
\end{tabular}

Fonte: Os Autores

REAd | Porto Alegre - Edição 76 - N 3 - setembro/dezembro 2013 - p. 738-766 
A influência do sistema de avaliação da AACSB na gestão dos programas de Pós-Graduação Stricto Sensu em Administração nos Estados Unidos

Ao analisar as respostas do quadro 4 acima, percebe-se os programas da área de Administração buscam credenciamento para assegurar a melhoria contínua da qualidade e, principalmente, para se distinguirem da concorrência, melhorando a sua competitividade no intuito de atrair os melhores alunos e professores.

Estar credenciado é um fator de reputação para a UMASS e a CSU, que são programas públicos, grandes e, há mais tempo, participam do processo de avaliação, que lhes confere o reconhecimento da comunidade. Já para os programas das CCSU e da QU, que fazem parte a menos tempo do processo de avaliação e credenciamento da AACSB, fazer parte desse sistema os distingue dos concorrentes, que não possuem certificação. Ou seja, o credenciamento é um fator de competitividade na atração de professores e alunos.

Nesta linha, Durham (2006) afirma que a competição é um fator inerente à cultura norte-americana: as IES competem por prestígio, por alunos com potencial e por professores de renome internacional, o que leva a constante renovação do quadro de docentes e do processo desenvolvido para atrair graduados promissores para a formação profissional e pósgraduada. Assim, o credenciamento da AACSB parece ajudar os programas no processo de “caça a talentos", destacado por Durham (2006).

Outro ponto de destaque é que o credenciamento também ajuda a organizar o programa, fazendo com que as pessoas estejam mais atentas com suas responsabilidades, com a docência e a pesquisa. Porém, o processo de avaliação, exige um grande esforço financeiro e de pessoal por parte da instituição para manutenção do credenciamento.

\subsection{Corpo docente}

Quadro 5 - O processo de contratação de docentes

\begin{tabular}{|l|l|}
\hline \multicolumn{2}{|c|}{3 - O sistema tem influenciado no processo de contratação de novos docentes? } \\
\hline UMASS & $\begin{array}{l}\text { De certa forma sim, pois ele nos indica onde precisamos reforçar nosso time. Porém, o nosso } \\
\text { processo é gerido mais pela Universidade, ela é quem define as regras para a contratação. }\end{array}$ \\
\hline CSU & $\begin{array}{l}\text { Sim, mas precisamos cumprir as normas estabelecidas pela universidade. Atendidas essas normas, } \\
\text { então nós olhamos os currículos dos professores para que eles possam se integrar ao time e ajudar- } \\
\text { nos a melhorar os critérios exigidos pela AACSB. Outro fato é que nós procuramos contratar } \\
\text { professores provenientes de programas credenciados. }\end{array}$ \\
\hline CCSU & $\begin{array}{l}\text { Sim, pois todos os professores devem ter doutorado para serem enquadrados nas qualificações } \\
\text { profissional ou acadêmica) exigidas pela AACSB, porém nossa missão é muito genérica e qualquer } \\
\text { um pode ser contratado. }\end{array}$ \\
\hline QU & $\begin{array}{l}\text { Sim, pois temos que contratar professores doutores provenientes de programas credenciados pela } \\
\text { AACSB. Analisamos o campo de pesquisa do professor para ver se isso atende às exigências da área } \\
\text { específica e aos critérios da AACSB. }\end{array}$ \\
\hline
\end{tabular}

REAd | Porto Alegre - Edição 76 - N 3 - setembro/dezembro 2013 - p. 738-766 
Emerson Antonio Maccari, Edson Luiz Riccio \& Cibele Barsalini Martins

Fonte: Os Autores

No quadro 5 acima, verifica-se que o sistema de avaliação da AACSB exerce influência na contratação dos docentes em maior grau nas mais novas no processo de avaliação (QU e CCSU), sendo que, nestas, as demandas do sistema de avaliação direcionam o perfil de contratação dos professores. Já nos programas de universidades maiores e mais consolidadas, com mais tempo no processo de avaliação no caso a UMASS e CSU, a própria universidade estabelece as regras e eles procuram contratar professores que atendam às regras estabelecidas pela universidade e que também atendam às demandas do sistema de avaliação da AACSB. Observa-se também a tendência de se contratar professores de programas também credenciados pela AACSB, o que indica o valor real de se possuir o credenciamento, haja vista que o sistema de avaliação da AACSB indica a necessidade de o programa possuir docentes capazes de garantir a qualidade das atividades de ensino.

Quadro 6 - Administração do fluxo docente

\begin{tabular}{|l|l|}
\hline \multicolumn{1}{|c|}{4 - Administração do fluxo docente (entrada e saída) ao longo da avaliação? } \\
\hline UMASS & $\begin{array}{l}\text { Existem critérios do sistema de avaliação que precisamos atingir, como o número de docentes } \\
\text { qualificados academica e profissionalmente. Para ser qualificado, tem que ter produção ou mostrar } \\
\text { experiência. É baixa a exigência de produção intelectual por parte do sistema de avaliação. } \\
\text { Basicamente o professor precisa ter dois artigos em periódicos com peer review nos últimos cinco } \\
\text { anos. }\end{array}$ \\
\hline CSU & $\begin{array}{l}\text { O sistema exige um número mínimo de professores qualificados academicamente e nós possuímos } \\
\text { para o doutorado 100\% dos professores nessa condição. Tem os critérios da AACSB para os } \\
\text { professores serem qualificados academicamente, mas nós temos um ranking próprio que é mais } \\
\text { exigente do que os dois artigos em periódicos em cinco anos. }\end{array}$ \\
\hline CCSU & $\begin{array}{l}\text { O sistema nos ajuda a definir os requisitos para um professor estar qualificado academicamente. Para } \\
\text { um programa como o nosso, os requisitos são menores do que um que possui um programa de } \\
\text { doutorado. A participação de professores em conferência conta para esse quesito. }\end{array}$ \\
\hline QU & $\begin{array}{l}\text { Existem critérios da AACSB que nós seguimos para definir quais professores fazem parte do quadro. } \\
\text { Para serem qualificados academicamente eles precisam ter cinco contribuições acadêmicas (um } \\
\text { artigo em periódico, parecer de artigo científico e participar de conferências) em cinco anos. }\end{array}$ \\
\hline
\end{tabular}

Fonte: Os autores

O sistema de avaliação da AACSB possui a maioria dos critérios qualitativos, um dos poucos quantitativos diz respeito à exigência de que no mínimo $90 \%$ dos professores sejam qualificados acadêmicos ou qualificados profissionalmente. Para os cursos que possuem doutorado, exige-se um maior número de professores qualificados academicamente, mas sempre dependendo da missão do programa. A performance do professor, para estar qualificado academicamente, leva em consideração suas contribuições intelectuais nos últimos cinco anos nas seguintes categorias: a) pesquisas; b) contribuições para a prática de gestão; e c) disciplinas baseadas em conteúdos inovadores.

REAd | Porto Alegre - Edição 76 - N 3 - setembro/dezembro 2013 - p. 738-766 
A influência do sistema de avaliação da AACSB na gestão dos programas de Pós-Graduação Stricto Sensu em Administração nos Estados Unidos

Ao se analisar as respostas contidas no quadro 6 acima, percebe-se que o sistema de avaliação da AACSB possui regras de produção bastante diferentes para os níveis de programas (mestrado e doutorado) e mesmo dentro destes níveis existem diferentes exigências, o que vai depender da missão. Verifica-se também que a exigência de produção é para o quinquênio sendo que o professor precisa produzir cinco peças ao longo deste tempo. Observa-se que os sistemas de credenciamento das universidades mais tradicionais (UMASS e CSU) é mais exigente no sistema de avaliação da AACSB. Para os programas que possuem doutorado, o docente deverá produzir dois artigos em periódicos. Já para aqueles que têm mestrado, um artigo em periódico, somado a participações em congressos, à atividade de parecerista de revista científica, os quais contam como contribuições científicas. No entanto, a definição do número de produções exigidas depende necessariamente da missão.

Quadro 7 - Atividades de ensino e orientação

\begin{tabular}{|l|l|}
\hline \multicolumn{2}{|c|}{5 - Equilíbrio e a distribuição das atividades (ensino e orientação) entre os docentes? } \\
\hline UMASS & $\begin{array}{l}\text { Não existe uma distribuição equitativa, pois depende muito do chefe do departamento. Se existe um } \\
\text { professor que é muito bom na produção, talvez ele lecione só um curso. A média são dois cursos por } \\
\text { semestre. Porém há professores que não precisam publicar, somente lecionar. }\end{array}$ \\
\hline CSU & $\begin{array}{l}\text { Nós temos o sindicato dos professores que define o número máximo de cursos que o professor pode } \\
\text { lecionar no ano. Para os professores que não produzem, precisam lecionar mais, para os outros, } \\
\text { existe um percentual que deve ser dedicado à docência, à pesquisa e à extensão. }\end{array}$ \\
\hline CCSU & $\begin{array}{l}\text { Temos o sindicato que especifica qual a carga de aula para os professores. Isso é medido pelo } \\
\text { número de alunos que cada professor pode lecionar ao longo do ano. Há também a expectativa de } \\
\text { produção por ano, como a participação de congressos ou a publicação de artigo em periódico. }\end{array}$ \\
\hline QU & $\begin{array}{l}\text { Estamos tentando reduzir a carga letiva dos professores que fazem muita pesquisa e produção } \\
\text { intelectual. Tentamos balancear a carga letiva pela produtividade do professor. Quanto mais } \\
\text { produtivo, menos carga de docência. }\end{array}$ \\
\hline
\end{tabular}

Fonte: Os Autores

Ao analisar o sistema de avaliação da AACSB, para esta questão, verifica-se que não existe a exigência individual para os professores. Há a exigência para o conjunto de professores, sendo que $75 \%$ deles devem lecionar em, pelo menos, $60 \%$ das disciplinas. Os professores devem estar distribuídos pelos cursos e disciplinas consistentes com a missão do programa. Assim, não existe a exigência do sistema da AACSB pelo equilíbrio na carga de ensino e orientação dos docentes.

No quadro 7 acima, pode-se observar que a carga letiva é regulada pelo sindicato da categoria, que estabelece um número máximo para o docente. Nesse sentido, cabe aos programas ajustarem e dimensionarem seu corpo docente, para realizarem as atividades de 
Emerson Antonio Maccari, Edson Luiz Riccio \& Cibele Barsalini Martins

docência e orientação. Porém, os professores mais produtivos recebem menos cargas letivas dos que são menos produtivos e alguns professores não precisam produzir, somente lecionar.

\subsection{Corpo discente/egresso - AACSB}

Quadro 8 - Formação Discente

\begin{tabular}{|l|l|}
\hline \multicolumn{1}{|c|}{6 - Influência do sistema de avaliação na formação discente? } \\
\hline UMASS & $\begin{array}{l}\text { O sistema ajuda a definirmos o tipo de estudante que desejamos formar, isso está em nossa missão. } \\
\text { Então precisamos alinhar a nossa estrutura curricular de modo a oferecer um curso que dê condições } \\
\text { ao aluno obter um diferencial em sua carreira. Cabe destacar que não existe uma taxa mínima de } \\
\text { formação de alunos num determinado tempo. }\end{array}$ \\
\hline CSU & $\begin{array}{l}\text { O sistema da AACSB possui critérios para avaliar o processo de aprendizagem dos nossos alunos e } \\
\text { isso nos direciona a verificar constantemente os resultados desse processo em relação com os } \\
\text { objetivos de aprendizagem estabelecidos em nosso plano estratégico. O sistema não exige a } \\
\text { formação do aluno em um determinado prazo. }\end{array}$ \\
\hline CCSU & $\begin{array}{l}\text { O sistema também estabelece metas de aprendizagem dos nossos alunos de acordo com nossa } \\
\text { missão. Porém o sistema não fala nada em relação ao prazo para a titulação do aluno. }\end{array}$ \\
\hline QU & $\begin{array}{l}\text { O sistema não cobra um tempo mínimo para formação dos nossos alunos, mas ele possui critérios } \\
\text { para avaliar o processo de aprendizagem do aluno, se estamos cumprindo o que nos propomos na } \\
\text { nossa missão. }\end{array}$ \\
\hline
\end{tabular}

Fonte: Os Autores

O sistema de avaliação da AACSB possui o processo de formação discente bem detalhado. Isso também leva em consideração a quantidade de cursos que cada professor pode lecionar em um ano (no máximo 3), pois a AACSB entende que o professor precisa ter tempo para preparar as atividades letivas e também para pesquisar. Existe ainda uma série de habilidades e conhecimentos que são requeridos dos alunos do mestrado e do doutorado e devem ser abordados ao longo do curso. Adicionalmente, o programa deve prover o tempo suficiente para o aluno assimilar o conteúdo e incentivar a interação professor-aluno, para assegurar que os objetivos de aprendizagem sejam alcançados.

Assim, nas respostas dos coordenadores contidas no quadro 8 acima, percebe-se que o sistema induz os programas a avaliarem constantemente a formação do discente, estabelecendo metas de aprendizagem para cada nível de curso, visando atender a missão. Não há exigência por parte do sistema sobre o tempo médio de titulação dos alunos, ou seja, sobre a eficiência na formação discente. 
A influência do sistema de avaliação da AACSB na gestão dos programas de Pós-Graduação Stricto Sensu em Administração nos Estados Unidos

Quadro 9 - Acompanhamento do Egresso

7 - Existe um sistema para acompanhamento do egresso?

\begin{tabular}{|l|l|}
\hline UMASS & $\begin{array}{l}\text { Existe, apesar do egresso não ser um item específico do sistema de avaliação. Nós entendemos que } \\
\text { ele é uma parte importante no sistema como um todo, pois precisamos informar a AACSB como } \\
\text { estamos atendendo os nossos stakeholders, assim o egresso é um dos principais stakeholder. } \\
\text { Informamos a AACSB sobre quantos dos ex-alunos se tornaram professores em outros programas, } \\
\text { quantos estão trabalhando em organizações, quanto eles estão ganhando. }\end{array}$ \\
\hline CSU & $\begin{array}{l}\text { Temos uma associação atuante de ex-alunos (ALUMNI) que participa da vida do programa e ajuda } \\
\text { com doações. A AACSB incentiva o programa: a saber como estão profissionalmente seus ex- } \\
\text { alunos, quanto eles estão ganhando e onde estão atuando. }\end{array}$ \\
\hline CCSU & $\begin{array}{l}\text { O sistema da AACSB valoriza de forma indireta a formação do aluno e a participação do ex-aluno } \\
\text { (egresso) no programa. Qual foi o papel que programa teve na vida profissional do aluno. Por isso o } \\
\text { programa procura saber informações profissionais desses alunos. }\end{array}$ \\
\hline QU & $\begin{array}{l}\text { O egresso é muito importante para o programa e o sistema da AACSB procura saber as informações } \\
\text { profissionais deles. Temos uma associação atuante, que participa efetivamente da vida do programa. } \\
\text { Eles também fazem doações e isso é algo que é valorizado por nós. }\end{array}$ \\
\hline
\end{tabular}

Fonte: Os Autores

Nas respostas contidas no quadro 9 e ao se analisar o sistema da AACSB, verifica-se que não há um item específico que trata do egresso, porém quando os programas montam o relatório anual, eles precisam descrever como suas atividades estão sendo realizadas, no intuito de atender aos interesses e necessidades dos stakeholders. Neste ponto, os programas dão destaque ao egresso, pois ele é um dos stakeholders mais importante. O egresso é basicamente o principal resultado do processo de avaliação da AACSB, sendo um fator decisivo na construção da reputação de um programa.

Percebe-se também a atenção dada pelos programas ao egresso no incentivo que eles dão para criação e a manutenção das associações dos ex-alunos (Alumni) e com isso manter o egresso próximo, participante da vida do programa. Assim, fica mais fácil obter informações, receber feedbacks dos egressos e, com isso, o programa pode identificar oportunidades de melhorias para formar ainda melhor seus alunos. Outro ponto destacado nas respostas dos coordenadores é a cultura de doação, ou fundraising que existe nos Estados Unidos e, por conseguinte, o egresso é um dos principais doadores nas universidades. Neste sentido, o egresso tem muito interesse que a universidade onde realizou os seus estudos, continue desfrutando de prestígio, pois a reputação da universidade impacta diretamente no desenvolvimento de sua carreira.

\subsection{Inserção social - AACSB}

REAd | Porto Alegre - Edição 76 - N 3 - setembro/dezembro 2013 - p. 738-766 
Emerson Antonio Maccari, Edson Luiz Riccio \& Cibele Barsalini Martins

Quadro 10 - Inserção Social

\begin{tabular}{|l|l|}
\hline \multicolumn{1}{|c|}{8 - Ações para aumentar a inserção social? } \\
\hline UMASS & $\begin{array}{l}\text { Não existe essa exigência no sistema de avaliação, nós temos que cumprir nossa missão e atender aos } \\
\text { nossos stakeholders, mas não há nada de específico sobre isso. }\end{array}$ \\
\hline CSU & $\begin{array}{l}\text { Não existe exigência nesse aspecto pelo sistema da AACSB. O nosso objetivo é formar recursos } \\
\text { humanos com qualidade. Acredito que se fizermos isso, estamos cumprindo a função social. }\end{array}$ \\
\hline CCSU & $\begin{array}{l}\text { Isso não é uma exigência do sistema de avaliação. Porém procuramos formar bem nosso aluno e } \\
\text { assim melhorar nossa inserção social. }\end{array}$ \\
\hline QU & $\begin{array}{l}\text { Não existe uma demanda do sistema da AACSB em relação à inserção social, porém nós procuramos } \\
\text { atender aos anseios dos nossos stakeholders e formar alunos altamente qualificados. }\end{array}$ \\
\hline
\end{tabular}

Fonte: Os Autores

Ao analisar esta questão, quadro 10, verifica-se que o sistema de avaliação da AACSB não possui questões específicas para incentivar a inserção social. Entretanto, no entendimento dos programas avaliados, estes acreditam que estão cumprindo sua função social, ao formar recursos humanos qualificados, para atuarem nas organizações..

Existe uma grande preocupação com o processo de ensino e aprendizagem, o que exige a revisão contínua e sistemática da grade curricular e do conteúdo programático, bem como a avaliação dos resultados do processo de aprendizagem. Ademais, a matriz curricular deve levar em consideração as demandas dos stakeholders e a missão do programa. Os diretores entrevistados demonstraram acentuada preocupação com o cumprimento dos requisitos de qualidade e com adequação da matriz curricular à formação discente proposta pelo programa. Desta forma, os programas acreditam que contribuindo com a comunidade e, consequentemente, ampliando sua inserção social.

Fica evidente que o sistema da AACSB é um sistema utilitarista, uma vez que a formação de pessoas qualificadas é o principal produto por ele avaliado. Nessa concepção, a produção intelectual e a inserção social é uma consequência dessa formação.

O processo de avaliação da educação é um fenômeno que vem sendo adotado por vários países, alguns com maior, outros com menor grau de interferência do Estado. Nessa linha, Afonso (2000) destaca que, a partir da década de 1980, o interesse dos governos pela avaliação passou a denominar-se "Estado avaliador", expressão que traduz o estilo competitivo de governos que importam modelos de gestão privada para o domínio público, ou seja, seguem a lógica de mercado, com foco apenas nos resultados.

Nesse contexto, o processo de avaliação adotou uma nova dinâmica: passou a reunir informações para que o Estado tenha subsídios para orientar financiamentos, canalizar as pressões sociais por acesso ao ensino de qualidade e, assim, atender às demandas do setor

REAd | Porto Alegre - Edição 76 - N 3 - setembro/dezembro 2013 - p. 738-766 
A influência do sistema de avaliação da AACSB na gestão dos programas de Pós-Graduação Stricto Sensu em Administração nos Estados Unidos

produtivo (SCHWARTZMAN, 1990; DURHAM, 1992). Contudo, o Estado não deveria utilizar a avaliação somente como instrumento de centralização e pressão unilateral (DURHAM, 1992 e 2006), ou para vigiar e punir (FOUCAULT, 1983).

\section{CONSIDERAÇÕES FINAIS}

Neste trabalho, partiu-se do pressuposto de que a avaliação da educação é um elemento essencial para o desenvolvimento da nação e de que a pós-graduação é um instrumento eficiente para a formação e qualificação de recursos humanos, os quais contribuam, de forma decisiva, para que o país se torne mais competitivo nas áreas de Ciências e Tecnologia. Assim, propôs-se um estudo que pudesse entender como o sistema de avaliação da AACSB influencia a gestão dos programas de pós-graduação stricto sensu em administração nos Estados Unidos. E, em última análise, contribuir para a gestão dos programas de pós-graduação no Brasil.

Como conclusões da pesquisa, verifica-se que o fio condutor do sistema de avaliação da AACSB orienta os programas a estabelecerem e cumprirem sua missão e atender a um padrão mínimo de qualidade, tendo uma forte participação dos stakeholders no processo. A forma de apoio do sistema de avaliação da AACSB à gestão dos programas fundamenta-se na exigência de especificação de um plano estratégico que contenha uma missão claramente definida, a qual oriente o direcionamento e a dinâmica da gestão do programa. Outro fundamento do sistema de avaliação da AACSB é o foco no perfil da formação do egresso. $\mathrm{O}$ programa exige processos de ensino e aprendizagem alinhados às necessidades ou demandas sociais da área de abrangência dos programas.

A natureza do sistema de avaliação da AACSB é essencialmente qualitativa, o que amplia sua flexibilidade e permite que os programas de pós-graduação criem suas próprias dinâmicas de gestão e desenvolvimento de competências, baseados na adaptação de suas missões ao contexto.

Finalmente, os programas de pós-graduação no Brasil poderiam se beneficiar de alguns requisitos do sistema de avaliação da AACSB. Por exemplo, utilizar a missão como fio condutor do programa, fazer um acompanhamento do egresso de forma mais estruturada, para poder medir com propriedade a contribuição do curso no desenvolvimento da carreira dos seus egressos. Adicionalmente, buscar atender as necessidades dos vários stakeholderes, não 
Emerson Antonio Maccari, Edson Luiz Riccio \& Cibele Barsalini Martins

somente a CAPES, ampliando assim, a inserção social do programa e sua efetiva contribuição para a sociedade.

\section{RECOMENDAÇÕES}

Com relação à continuidade de estudos nesta área, levando-se em consideração a importância da temática sugere-se:

$\checkmark$ Caracterizar as principais dificuldades enfrentadas pelos programas para cumprirem os requisitos do sistema de avaliação da AACB.

$\checkmark$ Verificar a influência do sistema na definição das estratégias dos programas, principalmente no atendimento dos stakeholderes e o acompanhamento dos egressos;

$\checkmark$ Avaliar a contribuição do sistema de avaliação da AACSB para a geração de conhecimento científico e aplicado (produção técnica ou tecnológica).

$\checkmark$ Estudar a influência do sistema da AACSB no processo de internacionalização dos programas;

$\checkmark$ Verificar a aderência e a possibilidade de se utilizar alguns critérios do sistema de avaliação da AACSB de forma complementar ao Sistema de Avaliação da CAPES.

\section{LIMITAÇÕES DA PESQUISA}

De acordo com Creswell (2009), descrever as limitações do estudo remete à especificação, a circunscrição do estudo em questão. Este autor afirma ainda que as formas de limitações podem ser: a) o método escolhido; b) a forma que os dados foram coletados e c) a análise dos dados.

Assim, esta pesquisa delimita-se à aplicação do sistema de avaliação da AACSB nos programas estudados na área de administração. Para a incorporação de alguns itens do sistema de avaliação da AACSB em programas de pós-graduação no Brasil carece de pesquisas complementares.

REAd | Porto Alegre - Edição 76 - N 3 - setembro/dezembro 2013 - p. 738-766 
A influência do sistema de avaliação da AACSB na gestão dos programas de Pós-Graduação Stricto Sensu em Administração nos Estados Unidos

\section{REFERÊNCIAS}

AACSB - The Association to Advance Collegiate School of Business. Institucional web page. Disponível em: http://www.aacsb.edu/accreditation/accreditedmembers.asp. Acesso em 10 de set. de 2013a.

Mission Statement. Disponível em: http://www.aacsb.edu/about/missionstatement.asp. Acesso em 10 de set de 2013b.

Accreditation Fees. Disponível em: http://www.aacsb.edu/accreditation/fees.asp . Acesso em 10 de set de 2013c.

AFONSO, A. J. Avaliação educacional: regulação e emancipação: para uma sociologia das políticas avaliativas contemporâneas. São Paulo: Cortez, 2000.

ALLEN, N. L. Avaliação em Larga Escala: Lições de Experiências. In: anais. Sociedade Brasileira Sociedade Brasileira para o Progresso da Ciência, 1995.

ALMEIDA JÚNIOR, V. de P.; CATANI, A. Mendes. Algumas características das políticas de acreditação e avaliação da educação superior da Colômbia: interfaces com o Brasil. Revista Avaliação do Ensino Superior: Universidade de Sorocaba - UNISO, v. 14, n. 3, p. 561-582, nov, 2009. Disponível em: http://www.scielo.br/scielo.php?script=sci_arttext\&pid=S141440772009000300003 . Acesso em 21/05/2012.

BARROW, C. The Strategy of selective excellence: redesigning higher education for global competition in a posindustrial society. Higher Education. Kluwer Academic Publishers, Netherlands, 1996.

CANHADA, D. I. Estratégia como prática social e resultados acadêmicos: o doutorado em Administração na USP e na UFRGS. 2009. Dissertação (Mestrado em Administração), Universidade Federal do Paraná.

CASTREJÓN DIEZ, J. Las Bases filosóficas de La planeación, H. Cámara de Diputados, LIV Legislattura, Comisión de Ciencia y Tecnología, México, 1991.

CONTERA, C. Modelos de avaliação da qualidade da educação superior. In: DIAS SOBRINHO, J. e RISTOFF, D. I. (org.). Avaliação Democrática - Para uma Universidade Cidadã. Florianópolis: Insular, 2002.

CRESWELL, J. W. Research Design: Qualitative, Quantitative, and Mixed Methods Approaches. Thousand Oaks, CA, 2009.

REAd | Porto Alegre - Edição 76 - Nº 3 - setembro/dezembro 2013 - p. 738-766 
Emerson Antonio Maccari, Edson Luiz Riccio \& Cibele Barsalini Martins

DAVOK, D. F. Modelo de Meta-Avaliação de Processos de Avaliação da Qualidade de Cursos de Graduação. 2006, 274 f. (Tese de Doutorado), Programa de pós-graduação em Engenharia de Produção, Universidade Federal de Santa Catarina, Florianópolis, 2006.

DOUGLASS, John Aubrey. A educação superior no EUA: passado e futuro. São Paulo: Revista Ensino Superior - UNICAMP, 2010. Disponível em: www.gr.unicamp.br/ceav/revistaensinosuperior/ed01_maio2010/ed_01/maio2010_educacaoE UA.php. Acesso em 20/02/2012.

DURHAM, E. R. A institucionalização da Avaliação. In: DURHAN, Eunice R e SCHWARTZMAN, Simon (org.). Avaliação do ensino superior. São Paulo: Edusp, 1992.

Avaliação. In STEINER, J. E. e MALNIC, G. Ensino Superior: Conceito e Dinâmica. São Paulo: Edusp, 2006.

EISENHARDT, K. M. Building Theories from Case Study Research. Academy of Management Review, v. 14, n. 4, 1989.

FLICK, Uwe. Uma introdução à pesquisa qualitativa. 2 ed. Porto Alegre: Bookman, 2004.

FOUCAULT, Michel. Vigiar e punir: nascimento da prisão. 2. ed. Petropolis: Vozes, 1983. $277 \mathrm{p}$.

GUIMARÃES, Reinaldo. O futoro da pós-graduação: avaliando a avaliação. Revista Brasileira de Pós-graduação, Brasília, v. 4, n.8, p. 282-292, dezembro 2007. Disponível em: http://www2.capes.gov.br/rbpg/images/stories/downloads/RBPG/Vol.4_8dez2007_Debates artigo3_n8.pdf . Acesso em 27/03/2011.

HARRIS, S. e SUTTON, R. Functions of parting ceremonies in dying organizations. Academy of Management Journal, v. 29, p. 5-30, 1986.

HERRIOTT, R. E; e FIRESTONE, W. A. Multisite qualitative policy research: Optimizing description and generalizability. Educational Research, v. 12 p. 14-19, 1983.

HOTSON, Howard. Don't look to the Ivy League. London Review of books. Vo. 33. No. 10, 2011. Disponível em: www.lrb.co.uk/v33/n10/howard-hotson/dont-look-to-the-ivyleague\#fn-asterisk. Acesso em 20/02/2012.

HOUSE, E. R. Tendencias em evaluación. Revista de Educación, n. 299, 1992.

LARRY, Aft. Evaluating higher education programs in quality. Quality Progress. V. 35, n. 10, 2002.

REAd | Porto Alegre - Edição 76 - N 3 - setembro/dezembro 2013 - p. 738-766 
A influência do sistema de avaliação da AACSB na gestão dos programas de Pós-Graduação Stricto Sensu em Administração nos Estados Unidos

MACCARI, E. A.. Contribuição à gestão dos programas de pós-graduação Stricto sensu em Administração no Brasil com Base nos Sistemas de Avaliação Norte Americano e Brasileiro. 2008, 250f. (Tese de doutorado), Faculdade de Economia Administração e Contabilidade da Universidade de São Paulo, São Paulo, 2008.

.; LIMA, M. C. ; RICCIO, E. L. . Uso do Sistema de Avaliação da CAPES por programas de pós-graduação em Administração no Brasil. Revista de Ciências da Administração (CAD/UFSC), v. 11, p. 1-15, 2009a. Disponível em: http://www.periodicos.ufsc.br/index.php/adm/article/view/13077 . Acesso em: 10 nov. 2011.

; ALMEIDA, M. I. R de ; NISHIMURA, A. T. ; RODRIGUES, L. C. A Gestão dos Programas de pós-graduação em Administração com Base no Sistema de Avaliação da CAPES. REGE. Revista de Gestão USP, v. 16, p. 1-16, 2009 b.

MARTINS, C. B. ; MACCARI, E. A. ; STOROPOLI, J. E.; ANDRADE, R. O. B. Influência das estratégias e recursos para o desenvolvimento dos programas de pós-graduação da área de Administração, Ciências Contábeis e Turismo no período de 2001 a 2009. Revista Gestão Universitária na América Latina - GUAL, v. 6, p. 146-168, 2013.

MARTINS, C. B. ; MACCARI, E. A. ; STOROPOLI, J. E. ; ALMEIDA, M. I. R. ; RICCIO, E. L. . A influência do sistema de avaliação nos programas de pós-graduação stricto sensu brasileiro. Revista Gestão Universitária na América Latina - GUAL, v. 5, p. 155-178, 2012.

MELLO, C. M.; CRUBELlATE, J. M.; ROSSONI, L. Dinâmica e Relacionamento e Prováveis Respostas Estratégicas de Programas Brasileiros de Pós-graduação em Administração à Avaliação da Capes: Proposições Institucionais a partir da Análise de Redes de Co-Autorias. Revista de Administração Contemporânea, Curitiba, v. 14, n.3, art. 3 pp. 434-457, mai/jun, 2010. Disponível em:

http://www.anpad.org.br/periodicos/arq_pdf/a_1060.pdf . Acesso em 27/03/2011 .

MILES, M. B. e HUBERMAN, A. M. Qualitative data analysis: an expanded sourcebook. 2ed. Oaks, CA: Sage, 1994.

MILES, M. P; HAZELDINE, M. F e MUNILLA, L. S. The 2003 AACSB Accreditation standards and Implications for Business Faculty: A Short Note. Journal of Education for Business, sep/oct, v. 80, n. 1, 2004.

MINTZBERG, H. e WATERS, J. Tracking Strategy in an entrepreneurial firm. Academy of Management Journal, v. 25, p. 465-499, 1982.

NASCIMENTO, L. F.. Modelo CAPES de avaliação: Quais as consequências para o triênio 2010-2012? Administração: Ensino e Pesquisa - RAEP. Administração: Ensino e Pesquisa: Rio de Janeiro. v. 11, n. 4, p.- 579-600, out/nov/dez 2010.

REAd | Porto Alegre - Edição 76 - N 3 - setembro/dezembro 2013 - p. 738-766 
Emerson Antonio Maccari, Edson Luiz Riccio \& Cibele Barsalini Martins

NEGRET, F. A identidade e a importância dos mestrados profissionais no Brasil e algumas considerações para a sua avaliação. RBPG. Revista Brasileira de Pós-graduação, Brasília, v.5. n.10. p. 217-225, dezembro de 2008. Disponível em:

http://www2.capes.gov.br/rbpg/images/stories/downloads/RBPG/Vol.5_10_dez2008/Debates _Artigo1_n10.pdf. Acesso em 27/03/2011.

OLIVEIRA, R. T. Q.; BOTELHO, E. N.; AMARAL, C. T. N.; ZOTES, L. P. Os Programas de Pós-graduação Stricto Sensu no Contexto das Avaliações CAPES E CNPq. IV Congresso Nacional de Excelência em Gestão, Rio de Janeiro, 2008. Disponível em: http://www.latec.uff.br/CNeg/documentos/anais_cneg4/T7_0012_0456.pdf . Acesso em 23/03/2011.

OLIVEIRA, T. R. Diferenças e convergências dos processos de avaliação da educação superior na Argentina, Brasil e Uruguai: Uma perspectiva comparada. In: Anais IX Colóqui Internacional sobre Gestão Universitária na América do Sul. Universidade Federal de Santa Catarina: Florianópolis, 25 a 27 de nov. de 2009. Disponível em: http://www.inpeau.ufsc.br/wp/wp-content/BD_documentos/coloquio9/IX-1060.pdf. Acesso em 21/05/2012.

RODRIGUES, C. M. C. Proposta de Avaliação Integrada ao Planejamento Anual: Um Modelo para as UCGs. Tese apresentada ao Programa de Pós-Graduação em Engenharia de Produção da Escola de Engenharia da Universidade Federal do Rio Grande do Sul - UFRGS. $341 \mathrm{f}$. Porto Alegre, 2003.

ROGGERO, P. Avaliação dos sistemas educativos nos países da União Européia: de uma necessidade problemática a uma prática complexa desejável. EccoS Ver. Cient., UNINOVE: São Paulo, n.2, v. 4, p. 31-46. Acesso:

www4.uninove.br/ojs/index.php/eccos/article/viewFile/307/295. Acesso em 21/05/2012.

SCHWARTZMAN, S. O contexto Institucional e político da avaliação do ensino superior. Nucleo de Pesquisas sobre Ensino Superior Universidade de São Paulo. USP: 3/90, 1990.

SOARES, M. S. A. O sistema de avaliação do ensino superior no Brasil. Disponível em: http://unesdoc.unesco.org.images/0013/001398/139881por.pdf . Acesso em 07/10/2013.

SOUZA, E. F. de. O Discurso da Capes para a avaliação dos programas de pósgraduação: da (des)fragmentação à comunicação em rede, $305 f$. Tese de doutorado. Departamento de Linguística, Português e Línguas Clássicas da Universidade de Brasília, 2008.

SPAGNOLO, F.; SOUZA, V. C. O que mudar na avaliação da CAPES? RBPG. Revista Brasileira de Pós-graduação, Brasília. V.1, n.2. p.8-34, nov, 2004. Disponível em: http://www2.capes.gov.br/rbpg/images/stories/downloads/RBPG/Vol.1_2_nov2004_/08_34_o _que_mudar_na_avaliacao_capes.pdf . Acesso em: 27/03/2011.

REAd | Porto Alegre - Edição 76 - N 3 - setembro/dezembro 2013 - p. 738-766 
A influência do sistema de avaliação da AACSB na gestão dos programas de Pós-Graduação Stricto Sensu em Administração nos Estados Unidos TOPUNIVERSITIES. QS World University Rankings 2011/12. Disponível em http://www.topuniversities.com/university-rankings. Acesso em 20 de jan. 2012.

WILLIS, D. Educational assessment and accountability: a New Zealand case study. Journal of Education Policy, v. 7. N. 2, 1992.

WOLFF. L. Evaluación Educacional en América Latina: Progresos Actuales y Desafíos Futuros. Programa de Promoción de La Reforma Educacional de América Latina y el Caribe. n. 11, 1998. Disponível em: http://www.preal.org/BibliotecaN.asp?Pagina=5\&Id_Carpeta=64\&Camino=63|Preal\%20Publ icaciones/64|PREAL\%20Documentos . Acesso em: 21/05/2012.

YIN, R. The case study crisis: Some answers. Administrative Science Quarterly, v. 26, p. 58-65, 1981.

Case study research. Beverly Hills, CA: Sage Publications, 1984.

Evaluation: A singular craft. In REICHARDT, C. \& RALLIS, S. New directions in program evaluation, p. 71-84. San Francico: Jossey-Bass, 1994.

Case study research: Design and methods. 3ed. Thousand Oaks, CA: Sage Publications, 2003. 